\title{
O HOMEM NA ERA DIGITAL
}

Maria Celeste de Sousa ${ }^{1}$

\section{Resumo:}

Este artigo discorre sobre o homem na era digital. Trata-se de refletir sobre a problemática do transhumanismo, tema antropológico persistente nas Ciências Humanas e, que é trabalhado, entre outros, pela filósofa portuguesa Maria Assumpta Coimbra, da Universidade do Porto. Ele está dividido em duas partes: a primeira versa sobre a cibercultura, o mundo como uma imensa teia digital e enfoca a influência da revolução tecnológica digital na cultura, na educação e nas ciências. A segunda parte versa sobre a transformação do humano em transhumano e reflete sobre o impacto das tecnologias digitais na natureza e na subjetividade gerando um logos-transumano e uma supranatureza.

Palavras chaves: Era digital. Cibercultura. Transhumano. Supranatureza.

\section{THE MAN IN THE DIGITAL ERA}

\begin{abstract}
:
This article discusses man in the digital age. It is a question of reflecting on the problem of transhumanism, an anthropological theme persistent in the Human Sciences and which is worked, among others, by the Portuguese philosopher Maria Assumpta Coimbra, from the University of Porto. It is divided into two parts: the first deals with cyberculture, the world as an immense digital web and focuses on the influence of the digital technological revolution on culture, education and sciences. The second part deals with the transformation of the human into a transhuman and reflects on the impact of digital technologies on nature and subjectivity, generating logos-transhuman and supranature.
\end{abstract}

Keywords: Digital age. Cyberculture. Transhuman. Supranature.

\section{Introdução}

Um olhar filosófico sobre a Tecnologia e Sociedade suscita a reflexão sobre o homem na era digital. Trata-se de refletir sobre a problemática do transhumanismo que, atualmente tornou-se um tema antropológico persistente nas Ciências Humanas e, que é trabalhado, entre outros, pela filósofa portuguesa Maria Assumpta Coimbra, da Universidade do Porto.

1 Doutora em Filosofia pela Pontifícia Universidade Católica de São Paulo-PUCSP (2009). Mestre em Filosofia Prática pela Universidade Estadual do Ceará-UECE (2000). Especialista em Filosofia da Educação pela Universidade Estadual do Ceará -UECE (1995). Graduada em Filosofia - UECE (1993), graduada em Teologia - ICRE (1989). Vice coordenadora do GT "Um Olhar Interdisciplinar sobre a Subjetividade Humana" (UECE-FCF), Coordenadora do Curso de Filosofia (FCF), Coordenadora do Grupo de Estudos Vazianos (GEVAZ) da FCF. Leciona Filosofia na Faculdade Católica de Fortaleza (FCF) e no CEJA Paulo Freire. Tem experiência na área de História da Filosofia, Metafísica, Ética, Antropologia Filosófica e Filosofia da Educação. Atua principalmente nos seguintes temas: História, Antropologia, Ética, Educação. E-mail: celestejosefina@gmail.com. 
O texto objetiva apresentar a reflexão de Maria Assumpta em diálogo com vários filósofos sobre o transhumanismo. Ele está dividido em duas partes: a primeira versa sobre a cibercultura, o mundo como uma imensa teia digital e apresenta o posicionamento de alguns filósofos contemporâneos perante a revolução tecnológica digital e sua influência determinante na cultura, na educação e nas ciências.

A segunda parte refere-se à transformação do humano em transhumano e reflete sobre a mutação antropológica que passa da compreensão moderna para a compreensão pós-moderna sob o impacto das tecnologias digitais na natureza e na subjetividade gerando um logos-transumano e uma supranatureza que modifica a ideia que o homem tem de si.

\section{O mundo como uma imensa teia digital}

O século XXI pode ser caracterizado como "uma imensa teia digital" que envolve o sujeito levando-o a separar-se progressivamente das experiências naturais, para vivenciar experiências virtuais. Este fenômeno cultural denota a configuração temporal da cibercultura e a mutação do humano para o transhumano.

A problemática da cibercultura tornou-se recorrente aos pesquisadores das Ciências Humanas e a Filosofia não poderia ficar ausente do debate. Em todo o mundo se multiplicam os pensadores dedicados ao estudo deste fenômeno e, com ele, da nova imagem de homem que está sendo gestada no tempo contemporâneo.

A filósofa portuguesa Maria Assumpta define a cibercultura como a

nova concepção de existência influenciada pela multimídia, pela realidade
virtual e pelas redes de comunicação digital, caso da internet, que nos
transporta a grande velocidade para mundos simulados e "on-line" onde
podemos penetrar e interagir com outras pessoas." (COIMBRA, 2010, p. 53).

Já o filósofo francês Pierre Lévy denomina este tempo de "tele presença generalizada", pois a cibercultura remete o sujeito para espaços desterritorializados onde as comunidades virtuais conectam-se universalmente possibilitando diferentes encontros, não mais no espaço físico e, sim, no espaço virtual. Daí a mudança significativa nos comportamentos dos internautas que superam os parâmetros existenciais da era industrial para parâmetros da era da informática. A consequência

\begin{tabular}{|l|l|l|l|l|}
\hline Qenista Dialectus & Ano 9 & n. 19 & Agosto-Dezembro 2020 & p. $135-148$ \\
\hline
\end{tabular}


desta interrelação virtual é a expansão das "mass-média", para o frenesi da prática do "self-média" através da comunicação individual, seja pela mensagem, seja pela foto ou pelo vídeo. O que importa é está conectado na teia cibernética.

O filósofo português Negroponte corrobora com o debate enfatizando a mutação da realidade para o virtual, quando afirma que,

nós estamos na era digital, em que a informação passa a ser canalizada e distribuída, não na modalidade de átomos, (revistas, jornais, livros...) exigindo a presença física, mas de bits, 'o mais pequeno elemento atômico do ADN da informação' um minúsculo elemento que 'não tem cor, tamanho, nem peso e pode viajar à velocidade da luz' E, que, por sua vez, possibilita a acessibilidade universal da informação em termos de maior rapidez, eficiência, bem-estar e personalização.” (NEGROPONTE, 1996, p. 21).

Para o filósofo francês Guy Debord esta é a "sociedade do espetáculo", em que a representação do mundo através do "mass-média" vai cedendo espaço para a criação de uma sociedade "que surge da simulação do mundo, fruto das redes telemáticas, do hipertexto, da multimídia interativa, da realidade virtual.” (DEBORD, 1972, p. 5).

Maria Assumpta vislumbra nesta tendência atual, um paradoxo, pois o fenômeno da teia digital é global, mas a imposição das redes sociais é particular, a consequência é a fragmentação dos costumes e valores locais e direcionamento da vida individual ao consumismo e narcisismo.

Ela explica:

a cibercultura com base nas tecnologias digitais em rede, representa uma cultura "capyleft" ao potencializar a apropriação coletiva, a distribuição, os processos de cooperação e de troca planetária, bem como a modificação criativa de obras, independente do local ou espaço físico e do estatuto identitário e sociocultural. Estes aspectos são materializados na crescente troca de informação e de conhecimentos e no trabalho coletivo partilhado sob diversos formatos: Web, chats, e-mails, blogs temáticos, fóruns de discussão, redes sociais, software livre, jogos on-line, etc. (COIMBRA, 2010, p. 55).

Então, o que pensar diante da interface homem e máquina na sociedade contemporânea? O prognóstico delineado por filósofos, sociólogos, psicólogos ou antropólogos é que em um futuro próximo a comunicação será mais com as máquinas do que com os sujeitos. Este fato é reverenciado pelo filósofo francês Pierre Lévy que ver positivamente a "complementariedade, da ação conjugada e dinâmica dos dois

\begin{tabular}{|l|l|l|l|l|}
\hline Gevista Dialectus & Ano 9 & n. 19 & Agosto-Dezembro 2020 & p. $135-148$ \\
\hline
\end{tabular}


fatores (analógico e digital) com vista à melhoria e aperfeiçoamento das atuações humanas." (LÉVY, 1997, p. 263). Pierre Lévy qualifica a era digital como "um novo patamar de hominização" exprimindo um novo desenvolvimento humanista.

Maria Assumpta, no entanto, alerta sobre o impacto destas inovações na subjetividade e sociabilidade humanas. Ela presente um perigo no ar, uma mutação na conduta da pessoa, que se torna uma presa das tribos digitais que determinam um estilo de vida e de interesses que devem ser rigorosamente seguidos. As consequências são evidentes nos sinais emitidos com mais frequência pelas crianças e jovens na "crescente incapacidade de concentração, motivada pela proliferação em excesso de estímulos comunicacionais.” (COIMBRA, 2010, p. 58).

Acrescenta-se a isto a dificuldade no convívio social, na prática cotidiana das relações intersubjetivas pela centralização em interesses pessoais e egocêntricos que inviabilizam a formação de um consenso social. Assumpta afirma: "este modo de produção e de processamento de informações ou de mensagens, não somente acarreta sofisticação, abundância informativa e diversificação dos emissores como, também, desencadeia stress e ansiedade.” (COIMBRA, 2010, p. 58). A filósofa portuguesa insiste na tomada de posição diante deste quadro de poluição informativa, e sugere uma indispensável delimitação entre a informação e o conhecimento.

O pedagogo francês Edgar Morin corrobora com o debate alertando também para o "perigo informacional", que não permite a diferença entre a subinformação e a sobreinformação, de tal forma que o sujeito envolvido pelas redes sociais não consegue mais interiorizar-se, porque não há espaço para a meditação e a reflexão sobre as diferenças entre as situações e os fatos, uma vez que ele está tomado pela poluição informacional.

Diante deste quadro existencial, Maria Assumpta assevera a necessidade da reflexão sobre a delimitação dos conceitos "informação", "digital” e "comunicação", bem como a pergunta sobre a utilidade e o valor da comunicação para a vida. A filósofa portuguesa comenta que, embora a imagem do 'homo communicans', afirme-se cada vez mais por meio da "mass-média", a comunicação em si é um termo tão banalizado, que não se sabe mais o seu verdadeiro significado. Todavia, se a imagem do homem contemporâneo liga-se necessariamente ao ser comunicante, isto exige uma nova reflexão antropológica.

\begin{tabular}{|l|l|l|l|l|}
\hline Qevista Dialectus & Ano 9 & n. 19 & Agosto - Dezembro 2020 & p. $135-148$ \\
\hline
\end{tabular}


A autora estabelece a relação entre a antropologia e a cibernética, ciência que estuda os sistemas e mecanismos de controle automático, a regulação e a comunicação nos seres vivos e nas máquinas, e juntamente com ela, a revolução do computador, como controle da informação. Ela dialoga com Wiener que considera a cibernética como uma ciência que preconiza uma revolução antropológica, já que ela inverte as posições entre corpo humano e o corpo artificial da máquina. $\mathrm{O}$ corpo humano é visto apenas como "uma rede de comunicações" e as máquinas como um "organismo vivo" capaz "de transformar mensagens de entrada (inputs) em mensagens de saída (outputs) e assim, serem capazes de mudar a relação que estabeleciam entre ‘inputs' e 'outputs”. (WIENER, 1954, p. 10).

Diante deste crescente desenvolvimento tecnológico, Maria Assumpta questiona: o excessivo aumento dos meios comunicativos possibilitou mais humanização, interajuda e diálogo intersubjetivo? Esta sociedade da comunicação é uma sociedade transparente?

O filósofo italiano Gianni Vattimo critica esta sociedade pós-moderna e a desconstrução das 'grandes narrativas' que considerava sempre "a humanidade como um todo e constituindo, no passado, as grandes formas de legitimação do poder." (VATTIMO, 1992, p. 10).

E Camps reconhece o aperfeiçoamento da comunicação, mas também diagnostica sintomas de não comunicação que prolifera em atitudes de individualismo feroz, competitividade, incompreensão e indiferença. O filósofo afirma:

\footnotetext{
a digitalização das relações sociais e da vida em geral, que constitui o deslumbramento contemporâneo, não deixa de transportar sérias reservas e limitações, ao nível de uma possível hiperfragmentação da realidade, da perda dos sentidos tradicionais da comunidade e de realidade, paralelamente à tendência, aparentemente contraditória, de globalização, omnipresença e unilateralidade." (CAMPS, 1996, p. 145).
}

Maria Assumpta impactada pela cibercultura reflete sobre a nova experiência de tempo. A teia digital funciona com base numa transmissão sincrônica, essencialmente identificada por um conjunto de "nós" interconectados no tempo presente, caracterizado pelo imediatismo, instantaneidade, simultaneidade e urgência. Um "tempo mundial” independente dos aspectos geográficos e históricos. É o tempo de um "presente dilatado" às fronteiras do mundo presente.

\begin{tabular}{|l|l|l|l|l|}
\hline Gevista Dialectus & Ano 9 & n. 19 & Agosto-Dezembro 2020 & p. $135-148$ \\
\hline
\end{tabular}


O homem-presente comprime o tempo negando-lhe os intervalos. $\mathrm{O}$ único fato a ter sentido expressa-se no vivido, no perceptível e representável minimizando, assim, as relações intersubjetivas, o reconhecimento do outro e as tradições. Há mais uma ligação, do que uma relação. O mundo não é mais comum.

Pelo fenômeno atual do zapping manipula-se o imaginário e o sonho humanos na era digital. O sujeito imobilizado em um sofá e com o comando eletrônico pode usufruir da interatividade e da virtualidade, tornando-se senhor do tempo e de suas próprias vontades ao conectar-se ao que lhe interessa e ao repelir o que desgosta; afastar o que lhe aborrece e silenciar o que lhe enfraquece. A filósofa portuguesa conclui: "E, neste sentido trata-se de uma liberdade nefasta porque nos fecha num mundo egóide e nos aprisiona, meramente, no nosso ponto de vista, nas nossas representações e na nossa vontade." (COIMBRA, 2010, p. 70).

O 'homo zappiens' que vive permanentemente na vertigem das imagens de assalto, na procura desesperada por uma imagem total que o fascine e transforme o seu frenesi em contemplação, acaba por não ver nada, nem saber nada, apesar da incomensurável paranoia de instrumentos cognitivos de que dispõe.

Este homem exteriorizado, voltado para o eterno instante, no desejo do imediato, na felicidade instantânea, denota um fascínio pelo fetiche e o desfrute do figurativo. É uma atitude mais passiva do que reflexiva e ativa. Ela comenta:

Este sujeito animado pela instantaneidade tecnológica, compelido pelos fluxos e atraído para um presente convertido em atualidade, pode consumar a sua realização pessoal e intersubjetiva no aqui e agora carregado de sensacionalismo e de emoções. Isto o pode fazer cair no paradoxo de que quanto mais se comunica e se informa, mais se desinforma ou, ainda, arrastálo para tornar a encenação pela realidade, ele se afoga em um oceano de imagens técnicas que, por sua vez, o podem impedir da distinção entre o que é real e o que é resultado da manipulação de imagens." (COIMBRA, 2010, p. 72).

Este é o sujeito atual no contexto cibernético. Um 'sujeito global' cuja visão de mundo é instantânea e ligada à rede, à comunicação digital universal. Preso ao "eterno presente" este sujeito confere que o ponto de partida é o mesmo de chegada, uma vez que ele experimenta o império do cotidiano, com sua pluralidade de códigos, itinerários e objetivos. Para que se possa compreender melhor este fenômeno, necessitase confrontar a transformação do humano em transhumano.

\begin{tabular}{|l|l|l|l|l|}
\hline Qevista Dialectus & Ano 9 & n. 19 & Agosto - Dezembro 2020 & p. $135-148$ \\
\hline
\end{tabular}




\section{A transformação do humano em transhumano}

O debate em torno da cibercultura denotou uma questão antropológica fundamental no tempo contemporâneo: a transformação do humano em transhumano. Maria Assumpta enfrenta a problemática em diálogo com alguns filósofos na tentativa em compreender as características existenciais que qualificam esta nova experiência do homem pós-moderno.

A progressiva des-antropomorfização atual incita a curiosidade da filósofa portuguesa. Ela se pergunta sobre as consequências antropológicas e existenciais advindas com a superação dos limites do orgânico e do advento do homem pósorgânico, prelúdio do homem pós-biológico ou da formação de uma supranatureza.

A filósofa dialoga com o cientista americano Katherine Hayles sobre o tema da supranatureza. O cientista analisa em seus textos, o processo atual de uma redução do sujeito a uma massa de informação incorpórea. Ele afirma: "o sujeito pós-humano é uma amálgama, uma coleção de componentes heterogêneos, uma entidade materialinformacional cujos limites sofrem contínua construção e reconstrução.” (HAYLES, 1999, p. 13 in COIMBRA, 2010, p. 89, Citação 6). O cientista refere-se à transformação cultural hodierna em que surgem novos horizontes que impactam inevitavelmente na avaliação dos níveis das crenças, dos valores, das convicções e da estruturação da vida individual e coletiva.

Para o filósofo português Martins esta perspectiva cultural se compara aos dois clássicos da literatura: O Prometeu de Ésquilo e o Fausto de Goethe. Ele comenta:

a lição contida no mito do Prometeu é a revelação de que a humanidade não deve cair na arrogância de arrebatar as prerrogativas divinas. Há que persistir na defesa que os artifícios técnicos têm que constituir meros alargamentos ou projeções da capacidade corporais humanas e, nunca, efetivar uma ilimitada mecanização e/ou virtualização do corpo, ou mesmo, a superação de seu organicismo. (MARTINS, 2000 p. 13).

Fausto, por sua vez, confere à tecnologia poderes ilimitados, conduzindo

a uma expansão insaciável e sem ponderação das consequências do avanço tecnológico para a natureza e para a Humanidade (...) ele personifica a procura do saber além de todos os limites naturais, o acesso ao conhecimento proibido, à transgressão dos limites facultados pelo entendimento humano e a

\begin{tabular}{|l|l|l|l|l|}
\hline Qevista Dialectus & Ano 9 & n. 19 & Agosto - Dezembro 2020 & p. $135-148$ \\
\hline
\end{tabular}


consequente aspiração àquilo que é sublime e divino.” (MARTINS, 2000, p. 13 in Coimbra, 2010, p. 93).

Esta comparação denota o senhorio do homem sobre a natureza e sobre a vida e que a técnica não serve a qualquer objetivo humano. Sua especificidade é transformar os recursos e reservas disponíveis em matéria prima. Ciência e Tecnologia têm fins pragmáticos expressando a realização da vontade e do poder do homem.

Maria Assumpta assemelha a sociedade contemporânea ao espírito insaciável de Fausto devido ao frenesi das descobertas científicas na área das biotecnologias como os transgênicos, a clonagem, o genoma, a luta contra o envelhecimento e a morte. Acrescenta-se a isto os "projetos ligados à criação de programas computacionais evolutivos, de seres biomecânicos, e também à vida artificial." (COIMBRA, 2010, p. 93).

Outra característica que chama a atenção da filósofa portuguesa é a nova interpretação do corpo humano como ‘informação' podendo sofrer 'upgrades'. Como o que está em jogo é um impulso fáustico, pode-se alcançar a unidade absoluta entre sujeito objeto, no universo cibernético. As barreiras vencidas por Fausto conduz à transcendência da condição humana, para a manipulação e a criação de novas formas de vida e também de um logos-trans-humano, como afirma o filósofo Vallenilla: "o homem atravessa um momento decisivo em termos da evolução histórica daquilo que denomina 'ratio tecnica'." (VALLENILLA, 2004, p. 20), por conseguinte, constata-se na sociedade contemporânea uma crescente ultrapassagem da concepção moderna e antropomórfica de técnica para a metatécnica. Ele explica:

com a metatécnica emerge uma transracionalidade, caracterizada por ser 'trans-finita', 'trans-humana' e 'trans-óptica', não restringida simplesmente á violência e evidencia (meramente ópticas) que alimentavam o logos técnico tradicional. Vislumbra-se o advento de um novo 'logos', um 'logosmetatécnico', 'trans-humano' não de características antropomórficas, antropocêntricas e geocênctricas. (VALLENILLA, 2004, p. 21 in Coimbra, 2010, p. 98).

Este novo "logos" possibilita outras formas de inteligibilidade e de organização do real, que ultrapassa a propriedade exclusivamente visual, os limites inatos dos sentidos humanos, porque ele substitui radicalmente os fundamentos

\begin{tabular}{|l|l|l|l|l|}
\hline Qevista Dialectus & Ano 9 & n. 19 & Agosto - Dezembro 2020 & p. $135-148$ \\
\hline
\end{tabular}


ontológicos e epistemológicos e a própria técnica como expoente de racionalidade. Vallenilla explica:

\begin{abstract}
os novos modos de operar técnico, as ferramentas e os mecanismos utilizados, espécie de sentidos artificiais, subvertem os limites e as funções dos sentidos humanos congênitos, provocam mudanças profundas em termos de apreensão, organização e compreensibilidade, tudo isto, no sentido de consolidar o homem como dono e senhor do universo. (VALLENILLA, 2004, p. 13).
\end{abstract}

O homem torna-se o centro do universo e faz inúmeras descobertas a partir das infinitas possibilidades para o seu conhecimento e prática. De fato, ele experimenta uma supranatureza livre da estrutura originária e de suas energias conaturais, almejando "criar novas estruturas e reordenamentos da matéria mediante os quais obtenha o domínio da natureza em geral, quer dizer, num sentido estritamente galáctico.” (VALLENILLA, 2004, p. 50)

No pensamento de Vallenilla a razão humana tem a capacidade de construir uma supranatureza com os seus nexos que modificam e transcendem a relação natural. Vallenilla defende a tese de que

este projeto inerente à metatécnica, de modo significativo, não pode ser conotado de "i-racional" ou de "a-racional", mas a manifestação de um 'logos transhumano' que, por sua vez, aufere engrandecimento e outros redimensionamentos à racionalidade humana. (VALLENILLA, 2004, p. 50 in Coimbra, 2010, p. 96).

Maria Assumpta compreende que este "logos-transhumano" define a função demiúrgica do homem em seu livre arbítrio e vontade manipuladora da natureza. E que este logos substitui as seguintes categorias antropológicas: corporalidade, finitude, mortalidade, contingência e animalidade uma vez que o ser humano cada vez mais se limita "a um mero processador de informação" sendo a técnica "caracterizada como uma forma de extensão do corpo humano." (COIMBRA, 2010, p. 97). Por conseguinte, o avanço tecnológico expressa, como afirma Ferreira, uma

desconstrução nas dicotomias tradicionais como: alma/corpo, imanente/transcendente; matéria/forma; substância/acidente, matéria/espírito, homem/máquina, humano/não humano, natural/artificial e natureza/cultura. (FERREIRA, 2002, p. 223 in Coimbra, 2010, p. 102).

\begin{tabular}{|l|l|l|l|l|}
\hline Qevista Dialectus & Ano 9 & n. 19 & Agosto-Dezembro 2020 & p. $135-148$ \\
\hline
\end{tabular}


A linguagem antropológica também se modifica, uma vez que os sistemas orgânicos são descritos conforme os termos de processamento da informação, e os dispositivos mecânicos e informacionais (software, por exemplo) passam a ser explicados com uma linguagem idêntica. A tecnologia avança do biológico para o mundo das máquinas possibilitando uma "convergência de vida orgânica e inorgânica. Inclusive a fronteira do vivo e do não vivo declara-se problemática, tornando-se cada vez mais difícil discernir a própria vida." (COIMBRA, 2010, p. 102).

Para Hayles estes fenômenos denotam a emergência de uma nova subjetividade constituída pelo cruzamento da materialidade da informática com a imaterialidade da informação. A consequência é a transformação do humano em transhumano "com base em numa concepção de informação desligada do corpo e onde as fronteiras entre humanos e computadores se diluem, pondo em causa o sujeito autônomo." (HAYLES, 1999, 2,3 in Coimbra, 2010, p. 102).

A autora reflete sobre a padronização do transhumano fora dos contornos e limites do humano e constata que este afirma-se

pelas capacidades supranaturais e eleva-se à condição de um apetrecho, uma espécie de sentidos artificiais, suscetível de alterar o modo de intervenção e de explicação do real.(...) projeta-se a expansão da racionalidade humana para um domínio trans-humano de inéditas possibilidades, equacionadas para além das limitações físicas, psicossomáticas e das coordenadas espaçotemporais. Acarreta significativas implicações quer na definição de "eu”, da verdade e do cogito enfim, quer na própria concepção de homem (COIMBRA, 2010, p. 105).

A filósofa portuguesa questiona: é o fim da humanidade e a chegada do póshumano? O pós-humano é uma nova representação do homem ou um novo estágio a alcançar? Como nos tornamos pós-humanos?

Ela comenta que para o cientista americano Hayles estes fenômenos antropológicos não significam a morte da humanidade, mas, apenas "o fim de uma determinada concepção do humano.” (COIMBRA, 2010, p. 104). Katherine Hayles apresenta quatro características do homem pós-humano. Primeiramente, ele privilegia “o padrão informacional sobre a instância material, de tal modo que a incorporação num substrato biológico é vista como um acidente da história em vez de uma inevitabilidade da vida." (HAYLES, 1999: 2,3 in Coimbra, 2010, p. 108, citação 50).

\begin{tabular}{|l|l|l|l|l|}
\hline Qevista Dialectus & Ano 9 & n. 19 & Agosto - Dezembro 2020 & p. $135-148$ \\
\hline
\end{tabular}


Em seguida ele considera "a consciência como um epifenômeno, como um arrivista da evolução que tenta reivindicar para si todo o espetáculo quando na verdade não passa de um acontecimento lateral menor.” (Ibid., p. 108).

Posteriormente. Ele "pensa no corpo como a prótese original que todos aprendemos a manipular." E em quarto lugar, ele considera como mais importante a configuração do ser humano como "máquinas inteligentes". Por conseguinte, no homem pós-moderno não existem diferenças entre a "existência corporal e simulação de computador, mecanismo cibernético e organismo biológico, teleologia do robot e finalidades humanas" (Ibid., p. 108).

Então, o homem se resume em uma super máquina? o que acontece com a corporeidade? Os autores pós-modernos concordam que não existe um "corpo vivo" o que existe, de fato é um "corpo metamorfoseado" em texto, em ideia, em imagem desmaterializada, uma representação virtual.

Esta é a vitória da tecnologia em sua construção do pós-humanismo. Ela confere uma ruptura com o "perfil identitário" transmitido pela tradição antropológica libertando o humano dos limites do orgânico, pelo abandono da transcendência e estabelecendo novas bases para "a construção de identidades funcionais e múltiplas". (COIMBRA, 2010, p. 110).

Maria Assumpta explica:

atualmente, o sujeito é reduzido à superfície. A tônica é colocada numa descentração do humano em favor da máquina. O humano deixa de ocupar o lugar de destaque porque no paradigma da vida artificial a máquina torna-se o modelo para compreensão do humano. Assim, o humano é transfigurado em pós-humano. Preconiza-se a criação de vida dentro da máquina e a capacidade desta se pautar por um processo evolutivo. Defende-se a coevolução do homem e da máquina. (COIMBRA, 2010, p. 111).

Esta progressiva des-antropomorfização faz com que Maria Assumpta questione: Como perspectivar o futuro do humano convertido em pós-humano? Esta perspectiva significará a aniquilação do homem, ou um novo caminho que se abre no relacionamento entre homens e máquinas?

A autora não tem uma resposta pontual para estas indagações. $\mathrm{O}$ fenômeno do transhumanismo ainda constitui uma grande interrogação que interfere diretamente em todas as relações humanas. A filósofa portuguesa suscita aos intelectuais

\begin{tabular}{|l|l|l|l|l|}
\hline Govista Oialectus & Ano 9 & n. 19 & Agosto - Dezembro 2020 & p. $135-148$ \\
\hline
\end{tabular}


preocupados com o sentido da vida um aprofundamento sobre o transhumanismo para se perceber melhor a gravidade da problemática e, assim, evidenciar a importância da questão antropológica fundamental: quem é o homem?

\section{Considerações finais}

A temática "o homem na era digital" evidenciou os fenômenos atuais da cibercultura e o do transhumanismo e suscitou a reflexão sobre alguns aspectos que impactam a antropologia despertando novos questionamentos e alguns pontos de convergência com o debate.

O primeiro aspecto refere-se à qualificação do mundo como uma imensa teia digital que evidencia a supremacia da cibernética e do computador na vida humana transformando o mundo material em mundo virtual. Este mundo é profundamente atraente, sedutor, colorido, rápido e com infinitas possibilidades envolvendo crianças, jovens e adultos em sua teia, de tal forma que impera o ser humano exteriorizado, modelado pelo poder da máquina. Esta é uma realidade que precisa ser compreendida, refletida, e criticada. Será que as máquinas dominarão o mundo? Como estabelecer os limites na interface homem e máquina?

O segundo aspecto refere-se à estranheza diante da transformação do humano em transhumano e o limite em que se situa a imagem do sujeito pós-moderno cujas características restringem-se a um mecanismo de processamento de informação. A inversão entre máquina e homem é profundamente preocupante, pois o transhumano se manifesta como um "modelo informacional em detrimento do material", em que a consciência torna-se um acessório e não um "lugar da identidade". Em que o corpo é comparado à mera prótese manipulável e substituível, em que não há mais diferença entre "a existência corporal e a sua simulação em computador" ou entre um "organismo biológico e um mecanismo cibernético". Este novo corpo digital converte-se em pura imagem, numa subjetividade desencarnada. Humano ou desumano? Será que Deus e o homem estão mortos? Será que o niilismo é total? O que nos resta esperar?

$\mathrm{O}$ terceiro aspecto refere-se à defesa do logos trans-humano. Temática inovadora expressiva da mutação na linguagem antropológica, metafísica e ética para uma linguagem mecanicista e informacional, trans-humana. O mundo simbólico adquire

\begin{tabular}{|l|l|l|l|l|}
\hline Qevista Dialectus & Ano 9 & n. 19 & Agosto-Dezembro 2020 & p. $135-148$ \\
\hline
\end{tabular}


novas formas de expressão que também precisam ser compreendidas e aprofundadas. Qual o sentido da linguagem?

Quanto aos pontos convergentes destaca-se o sinal vermelho diante do impacto das inovações tecnológicas digitais na subjetividade e sociabilidade humanas. Este sinal de alerta se estende para todas as relações intersubjetivas suscitando uma tomada de posição de homens e mulheres que defendem a vida no planeta terra. Trata-se de um debate amplo sobre o "perigo informacional", que retira do sujeito a sua interioridade minimizando o espaço para a meditação e a reflexão sobre as diferenças entre as situações e os fatos tornando-o semelhante a um robô sem noção de realidade.

Enfim, nós concordamos com a proposta educativa de Edgar Morin. Só pela educação é possível desenvolver as potencialidades na percepção da verdade sobre o humano. O desenvolvimento da "consciência crítica" é imprescindível diante do individualismo, da competitividade, da incompreensão, da indiferença, da hiper fragmentação e da perda do sentido da vida. Este montante expressivo da era digital gera a despersonalização ilusória da euforia em estar conectado, Daí a dúvida: Quais as relações entre informação e saber? Entre Informação e conhecimento? Ou entre Informação e comunicação?

Concluímos com a impressão de que esta problemática está apenas começando, ainda precisamos de muitos debates para que possamos ver melhor a transformação que está acontecendo e, a necessidade de sabermos quem nós somos, ou o que seremos.

\section{Referências bibliográficas}

COIMBRA, Maria Assumpta. (Des)humano demasiado (des) humano. O homem na era digital uma reflexão com Pierre Lévy. Lisboa: Edições Afrontamento, 2010.

CAMPS. V. Paradoxos do individualismo. Lisboa: Relógio D`Água Editores, 1996.

DEBORD, G. A Sociedade do espetáculo. Lisboa: Edições Afrodite, 1998.

FERREIRA, J. “O alfabeto da vida: da reprodução à produção". Lua Nova Revista de Cultura e Política, pp. 55-56, 219-240, 2002.

HAYLES, R. "Haw the became posthuman: virtual badies". In.: Cybernetics, literature and informatics. Chicago e Londres: University of Chicago Press, 1999.

\begin{tabular}{|l|l|l|l|l|}
\hline Q Povista Dialectus & Ano 9 & n. 19 & Agosto-Dezembro 2020 & p. $135-148$ \\
\hline
\end{tabular}


LÉVY, Pierre. Cyberculture. Paris: Éditions Odile Jacob, 1997.

MORIN, Edgar. As grandes questões do nosso tempo. Lisboa: Editorial Notícias, 1997.

MARTINS, H. Ciência, técnica \& utopia. Ler livros e leitores, $N^{o} 48$, Fundação Círculo de leitores, pp. 63-70. 2000.

NEGROMONTE, N. Ser digital. Lisboa: Editorial Caminho, 1996.

VATTIMO, Gianni. A sociedade transparente. Lisboa: Relógio D`água Editores, 1992.

VALLENILLA, E.M. Fundamentos da meta-técnica. Lisboa: Edições Colibri, 2004.

WIENER, N. Cybernetics. Control and communications in the animal and the machine. Cambridge: The MIT Press, 1954.

\begin{tabular}{|l|l|l|l|l|}
\hline Q Povista Dialectus & Ano 9 & n. 19 & Agosto - Dezembro 2020 & p. 135-148 \\
\hline
\end{tabular}

